\title{
Fine Structure of Taste Buds Located on the Lamb Epiglottis
}

\author{
ROBERT D. SWEAZEY, CHRIS A. EDWARDS, AND BETH M. KAPP \\ Department of Biologic and Materials Sciences, School of Dentistry, University of \\ Michigan, Ann Arbor, Michigan
}

\begin{abstract}
Background: Taste buds located on the aryepiglottal folds and laryngeal surface of the epiglottis are the principal receptors responsible for the initiation of the laryngeal chemoreflex. In contrast to the wealth of information available concerning the ultrastructure of oral taste buds, little comparable data exists for taste buds located at the entrance to the larynx. Therefore, the present study was designed to investigate the fine structure of taste buds located on the lamb epiglottis.

Materials: Stained thick and semi-serial thin sections from taste buds located on the lamb epiglottis were examined with light and electron microscopy.

Results: Based on morphological criteria, three types of cells could be identified in the taste bud: Type I, Type II, and basal cells. Both Type I and Type II cells extended into the apical taste pore, but there were differences between these two cell types with regard to nuclear profiles, electron density, and the relative density of ribosomes, apical mitochondria, and rough and smooth endoplasmic reticulum. Basal cells did not extend a process into the taste pore. Nerve processes were observed throughout the taste bud. Synapses were observed between both Type I and Type II cells and nerve fibers. These synapses exhibited membrane thickenings and accumulations of clear and dense-cored vesicles of varying proportions in the taste cell cytoplasm adjacent to membrane specializations.

Conclusions: The taste buds located on the lamb epiglottis share several structural similarities to taste buds located in the oral cavity and other regions of the pharynx and larynx of many mammalian species. The presence of synapses on both Type I and Type II cells of the lamb epiglottal taste bud suggests that both cell types are involved in laryngeal chemoreception. (c) 1994 Wiley-Liss, Inc.
\end{abstract}

Key words: Electron microscopy, Epiglottis, Gustatory, Larynx, Reflex, Sheep, Synapse

Infusions of chemical stimuli into the larynx of most mammalian species, including man, initiate a protective reflex that includes both vigorous swallowing and apnea (Boggs and Bartlett, 1982; Davies et al., 1988; Harding et al., 1978; Johnson et al., 1975; Kovar et al., 1979; Lee et al., 1977; Lucier et al., 1979; Pickens et al., 1988; Storey, 1968; Storey and Johnson, 1975). The principal receptors thought to underlie the initiation of this laryngeal chemoreflex are taste buds located at the entrance to the larynx, primarily on the laryngeal surface of the epiglottis and aryepiglottal folds (Bradley, 1982; Bradley et al., 1980, 1983; Harding, 1984; Nakano and Muto, 1986; Thach et al., 1990).

In contrast to the wealth of information available concerning the morphological characteristics of oral taste buds (see reviews by Roper, 1989; and Murray, 1973), little comparable data exists for taste buds located at the entrance to the larynx. Light microscopic investigations in several species have described the morphology, development, and distribution of taste buds located at the entrance to the upper airway (Brad- ley et al., 1980; Lalonde and Eglitis, 1961; Nagano and Muto, 1986; Stedman et al., 1983; Travers and Nicklas, 1990; Wilson, 1905). In general, these investigations have shown that taste buds located at the entrance to the larynx appear morphologically similar to oral taste buds. Using electron microscopy Idé and Munger (1980) examined the structure of taste buds located in the epithelium overlying the monkey arytenoid cartilage. They described three cell types, undifferentiated basal cells, supporting cells, and based on the presence of synaptic contacts, chemosensory cells. Suzuki and Takeda (1983) examined the ultrastructure of taste buds located throughout the larynx and pharynx of the mouse and found many similarities to oral taste buds.

Received June 9, 1993; accepted October 25, 1993.

Address reprint requests to Dr. Robert D. Sweazey, Fort Wayne Center for Medical Education, 2101 Coliseum Blvd. East, Fort Wayne, IN 46805-1499. 
These similarities included three distinct cell types which extended apical processes into the taste pore and an undifferentiated basal cell. Like Idé and Munger (1980), these investigators found synapses on only one cell type which they classified as the Type III or receptor cell. The presence of synapses and concentrations of vesicles in only one cell type of upper airway taste buds in monkey and mouse are similar to characteristics reported for oral taste buds in several species (Farbman et al., 1985; Murray and Murray, 1971; Paran et al., 1975; Royer and Kinnamon, 1991; Takeda, 1976; Yoshie et al., 1990). However, investigations in some species, including recent studies that have examined mouse foliate and vallate taste buds, suggest that there are synapse-like structures on more than one cell type within the taste bud (Delay and Roper, 1988; Kinnamon et al., 1985, 1988; Reutter, 1978; Royer and Kinnamon, 1988).

Although the investigations of Idé and Munger (1980) and Suzuki and Takeda (1983) provide some information concerning the fine structure of non-oral taste buds, the species examined by these studies have rarely been used for the study of the laryngeal chemoreflex. Furthermore, these studies did not concentrate on taste buds located on the epiglottis where many of the taste buds located at the entrance to the upper airway are found. The epiglottis is also usually stimulated during behavioral studies and physiological investigations of the neural pathways which underlie the laryngeal chemoreflex.

The present study was designed to investigate the fine structure of taste buds located on the lamb epiglottis. The lamb was chosen because it has been widely used in behavioral, anatomical and physiological studies of the laryngeal chemoreflex (Bradley and Kim, 1977; Bradley et al., 1980, 1983; Grogaard et al., 1982; Johnson et al., 1975; Harding et al., 1977, 1978; Kovar et al., 1979; Sweazey and Bradley, 1986, 1988, 1989a,b; Storey and Johnson, 1975). Special attention was given to the identification of synapse-like specializations between nerve fibers and taste cells to determine if these structures were present on only one cell type within the bud as has been described for monkey and mouse laryngeal taste buds (Idé and Munger, 1980; Suzuki and Takeda, 1983), or on several different cell types as has been described for taste buds in mouse, mudpuppy and fish (Delay and Roper, 1988; Kinnamon et al., 1985, 1988; Reutter, 1978; Royer and Kinnamon, 1988).

\section{MATERIALS AND METHODS}

Experiments were performed on 6 Suffolk lambs, aged 30-60 days, with weights of 9-16 kg. These animals had previously been used for acute central nervous system electrophysiological recording experiments. The animals were given an overdose of sodium pentobarbital and perfused through the carotid arteries. The blood was flushed from the vascular system using 2 liters of heparinized $0.1 \mathrm{M}$ phosphate buffer $(\mathrm{pH} 7.2-7.4)$ at $39^{\circ} \mathrm{C}$, followed by 1 liter of a solution of $2 \%$ paraformaldehyde and $2 \%$ glutaraldehyde in $0.1 \mathrm{M}$ phosphate buffer at $39^{\circ} \mathrm{C}$. After perfusion, the epiglottis was removed and small blocks of epithelium were cut from areas of the laryngeal surface of the epiglottis that contain large numbers of taste buds (Stedman et al., 1980). The tissue blocks were then post-fixed in fresh fixative overnight at $4^{\circ} \mathrm{C}$.

Tissue blocks were rinsed in several changes of $0.1 \mathrm{M}$ buffer and post-fixed in $1 \% \mathrm{OsO}_{4}$ in $0.1 \mathrm{M}$ phosphate buffer. Specimens were dehydrated in an ascending series of ethanols followed by several changes of acetone. The tissue was infiltrated in 1:1 acetone-Epon resin under a vacuum followed by fresh Epon before embedding in Epon.

Thick longitudinal sections $(0.5 \mu \mathrm{m})$ were cut using glass knives, mounted on glass slides, and stained with methylene blue to locate taste buds in the epithelium. A total of sixteen taste buds were sectioned for electron microscopy. For 12 of the taste buds, several longitudinal thin sections $(70-85 \mathrm{~nm}$ ) from different regions of the taste bud were cut using a diamond knife. These sections were placed on uncoated 200-mesh grids or formvar coated slot grids, stained with uranyl acetate and lead citrate, and examined in a Philips EM 300 at 60 or $80 \mathrm{kV}$. In order to sample the entire structure of the lamb epiglottal taste bud, the remaining four taste buds were semi-serially sectioned. Every $2 \mu \mathrm{m}, 10$ to 20 longitudinal thin sections $(70-85 \mathrm{~nm})$ were cut using a diamond knife and processed as above. Thick sections that were collected between each group of thin sections were mounted and stained for light microscopic orientation as previously noted.

\section{RESULTS}

Taste buds located on the laryngeal surface of the lamb epiglottis were most numerous in blocks of tissue taken from the base or lateral margins of the epiglottis. The taste buds on the epiglottis extended from the base of the epithelium to the lumen of the larynx and were not associated with a papillae or any other specialization of the epithelium. It can be seen in Figure 1, that the taste buds had a typical goblet shape and contacted the lumen of the larynx via an apical pore in a manner similar to taste buds located in the oral cavity (Fig. 1). The taste pore was relatively shallow, filled with a heterogeneous mix of material of varying electron density and approximately $3-4 \mu \mathrm{m}$ wide (Fig. 1). The taste buds ranged in size from $40-60 \mu \mathrm{m}$ wide and $60-70$ $\mu \mathrm{m}$ high, and were frequently found in clusters of $2-4$ taste buds (Fig. 1, inset). The cells of the taste bud appeared to end in short brush-like microvilli or more blunt processes which extended into the taste pore (Fig. 2).

\section{Cell Types}

Based on morphological criteria, three types of cells could be identified in epiglottal taste buds. Because of the similarity of these cells to previously described cells in oral taste buds we have chosen to label them as Type I, Type II, and basal cells in accordance with the classification scheme of Murray (1973). The Type I (Dark) cells were encountered most frequently and were generally long and narrow. In semi-serial sections Type I cells were observed to extend from the base of the taste bud to the taste pore. The apical tip of Type I cells ended in several narrow, short, finger-like microvilli which contacted the lumen of the larynx via the taste pore (Fig. 2). Abundant dense granules and moderate to large numbers of small mitochondria were located in the apical portions of this type of cell (Figs. 2 

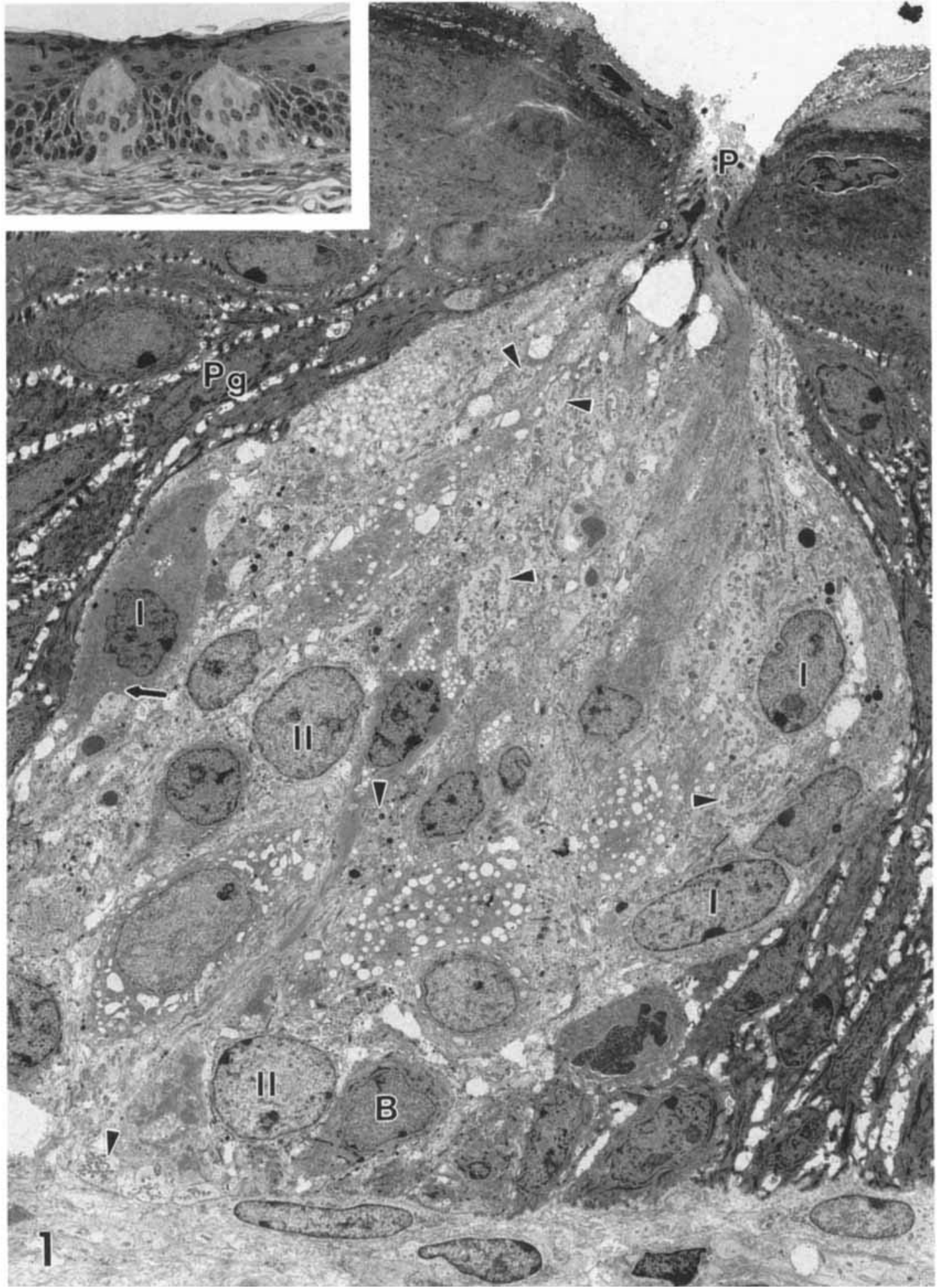

Fig. 1. Low power light micrograph (inset) and electron micrograph of taste buds on the laryngeal surface of the lamb epiglottis. The typical goblet shape of the taste buds, and clustering of taste buds can be seen in the inset. Examples of Type I, Type II, and basal cells are labeled in the electron micrograph. Several nerve processes (arrowheads) can be seen at the base and throughout the taste bud. A synapse-like apposition between a Type I cell and an adjacent nerve fiber can be seen at the far left of the bud (arrow). This region is shown at higher magnification in Figure 7. The taste pore at the top right of the figure is filled with material of varying electron density. Abbreviations: B, basal cell; I, Type I cell; II, Type II cell; P, pore; Pg, perigemmal cell. Electron micrograph, $\times 2,600$; inset: light micrograph, $\times 360$. 


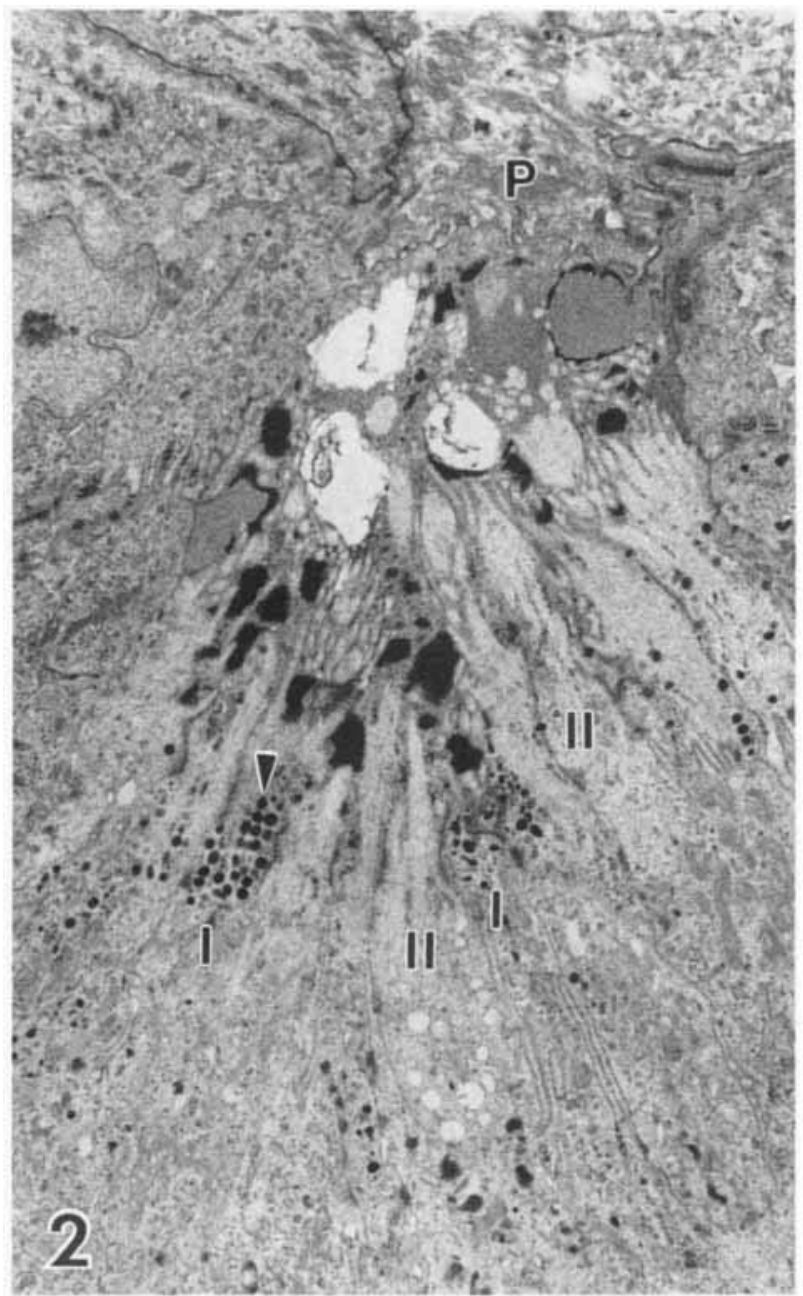

Fig. 2. Electron micrograph showing the pore and apical region of a taste bud on the lamb epiglottis. Large numbers of dark granuies can be seen in the apical cytoplasm of Type I cells (arrowhead). The apical portion of the taste cells can be seen ending in finger-like microvilli that extend into the taste pore. $\times 6,700$.

and 3). Type I cells were usually more electron dense than Type II cells although this was not always the case. The cytoplasm of Type I cells generally contained large numbers of rough endoplasmic reticulum, free ribosomes and polyribosomes. Large numbers of intermediate filaments were located throughout the cytoplasm, and tended to be concentrated in the perinuclear and infranuclear regions of the cell (Figs. 4-7). Lysosome-like dense bodies and an occasional densecored vesicle were scattered throughout the cytoplasm. The nuclei of Type I cells were usually oblong in shape and were often irregular and occasionally deeply indented (Fig. 1). The nuclear matrix was more electron opaque than that observed in Type II cells and patchy heterochromatin was frequently observed along the nuclear envelope (Fig. 1). In addition to the above characteristics, we also observed very electron dense Type I

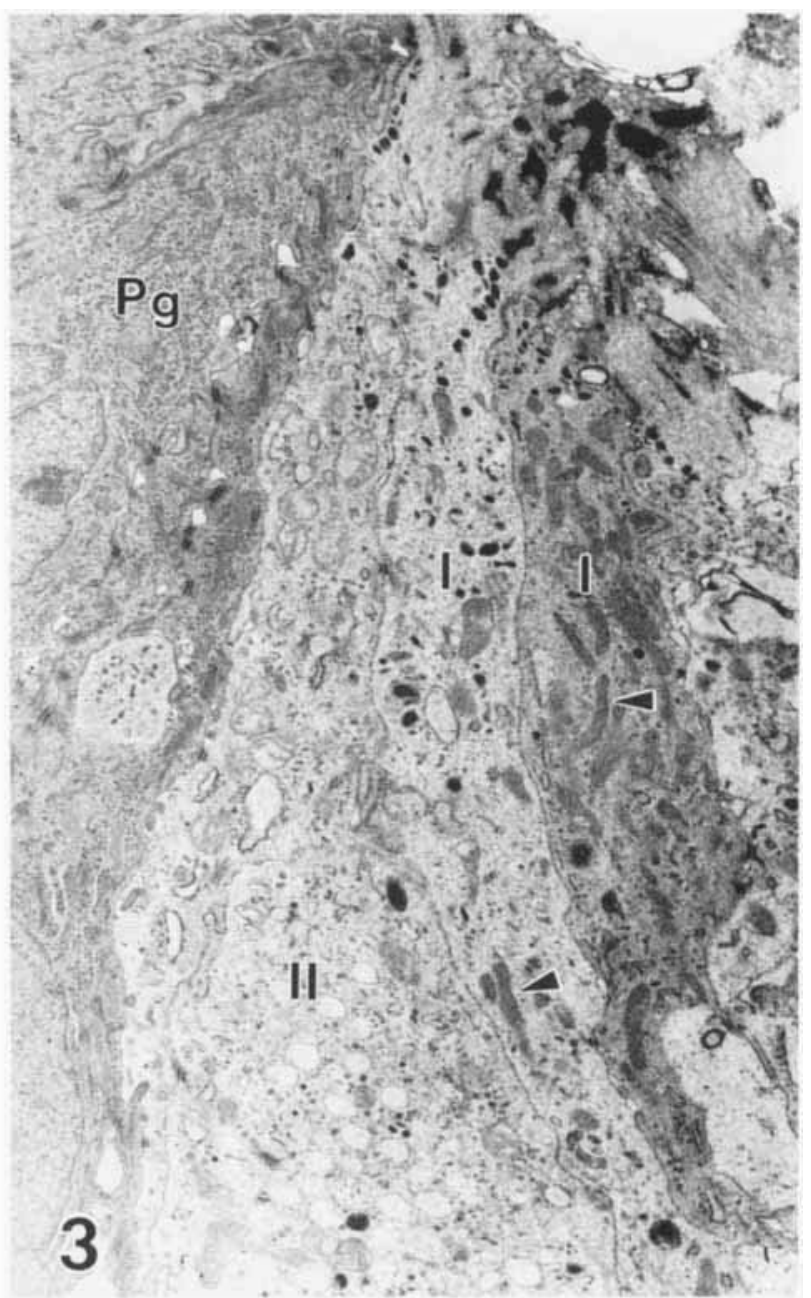

Fig. 3. Electron micrograph showing the apical cytoplasm of cells in a taste bud from the laryngeal surface of the lamb epiglottis. The Type I cells show the large numbers of rod shaped mitochondria (arrowheads) and dense granules which typify this class of cells. Note the variability in the electron density as well as number of mitochondria present in these two cells. A Type II cell can be seen to the left of the Type I cells. $\times 6,350$

cells that contained several electron lucent vacuoles in the supranuclear region (Fig. 1).

Type II (Light) cells were encountered less frequently in taste buds of the lamb epiglottis. Like Type I cells, in semi-serial sections Type II cells were seen to extend processes into the taste pore (Fig. 2). Type II cells generally had a more electron lucent cytoplasm that contained fewer free ribosomes and polyribosomes (Fig. 1). The apical portion of Type II cells lacked the large numbers of dense granules and mitochondria seen in Type I cells, and the Type II processes in the taste pore appeared more blunt than the microvilli of the Type I cells (Figs. 2 and 3 ). Type II cells contained smaller numbers of intermediate filaments and lysosome-like dense bodies than Type I cells, and smooth endoplasmic reticulum that was often irregular and dilated was located in the perinuclear and supranu- 
clear regions of the cell (Figs. 1 and 3 ). The nucleus of Type II cells was round to ovoid and usually contained a prominent nucleolus (Fig. 1). Type II cell nuclei were generally more electron lucent than Type I nuclei and the invaginations of the nuclear envelope were smaller and less frequent (Fig. 1).

Basal cells were located along the basolateral margins of the bud and adjacent to the basement membrane (Fig. 1). These cells were angular to flattened and had intermediate filaments near the nuclear membrane (Fig. 1). The cell cytoplasm and nucleus were generally moderately electron dense and the cytoplasm contained numerous rough endoplasmic reticulum. In the semi-serial sections we examined no basal cell extended processes to the level of the taste pore.

\section{Nerve Processes and Synapses}

Large numbers of nerve fibers were observed in lamb epiglottal taste buds (Fig. 1). The fibers contained clusters of mitochondria, scattered microtubules and neurofilaments, and were generally electron lucent (Figs. 4-6). Occasional clear and dense-cored vesicles were observed in these processes, but these vesicles were never concentrated adjacent to the nerve fiber membrane. Nerve processes were observed in all regions of the taste bud, but the majority were located in the basal two-thirds of the bud (Fig. 1). In semi-serial sections nerve fibers were observed to take a twisting path through the bud and nerve processes were located adjacent to all cell types (Figs. 4-6). Many nerve fibers were embedded in invaginations of the cell membrane, particularly near the cell nucleus (Figs. 5, 6).

We observed several synapse-like specializations between taste bud cells and apposed nerve fibers although it did not appear that every apposition between a nerve and taste bud cell exhibited synapse-like specializations. These synaptic specializations were observed between nerve fibers and both Type I and Type II cells. Similar specialized zones of apposition between basal cells $(\mathbf{n}=3)$ and adjacent nerve fibers were not observed. Figures 7-12 show examples of some of the synaptic specializations we observed between cells and nerve fibers in lamb epiglottal taste buds. The majority of specialized appositions occurred in the basal portions of the cell or near the cell's nucleus (Figs. 7 and 9). Synaptic specializations were characterized by a thickening of the presynaptic (taste cell) membrane and in some cases the postsynaptic membrane as well (Figs. 7-12). In favorable sections the thickening of the presynaptic membrane appeared as finger-like dense projections extending a short distance into the taste cell cytoplasm (Fig. 6). Furthermore, accumulations of small clear $(40-90 \mathrm{~nm})$ and larger dense-cored vesicles were observed in the taste cell in a small region adjacent to the membrane specialization (Figs. 7-9).

In general, there tended to be a larger number and more diffuse distribution of vesicles in the cytoplasm adjacent to synapses in Type II cells than in the cytoplasm adjacent to the synapses in Type I cells. In fact, we occasionally encountered Type II cells that contained large numbers of clear and dense-cored vesicles in the basal cytoplasm (Figs. 10-12). These vesicles were associated with a region of the cell that was apposed to the nerve process and in all cases the apposition between the cell and nerve process exhibited some specialization of the membrane resembling a synapse. However, the distribution of vesicles at these synapses was much more diffuse than that observed at all synapses associated with Type I cells (Figs. 7 and 9) and many Type II cells (Fig. 8).

The proportion of clear and dense-cored vesicles varied among the synapses examined with most synapses exhibiting a mixture of both types of vesicles (Figs. 7 and 12). In no case were concentrations of vesicles observed in any nerve fiber at these specialized zones suggesting that all the synapses examined were afferent in nature. Synapses were always macular in shape and in some cases the zone of membrane thickening extended along a large distance of the nerve-cell contact (Figs. 11, 12). Mitochondria were frequently located near the active region in both the nerve processes and taste cells (Figs. 9 and 11). Occasionally we observed a region of a taste cell where two or three nerve processes abutted the same region of the cell membrane (Figs. 11, 12). This close approximation of nerve processes resulted in a region of apposition over $4 \mu \mathrm{m}$ in length.

\section{DISCUSSION \\ Cell Types}

The present study describes the fine structure of taste buds located on the laryngeal surface of the lamb epiglottis. It was possible to classify most of the cells into one of three groups on the basis of morphological variations previously described by Murray (1973). These groups were Type I, Type II, and basal cells. Most of the morphological characteristics of the cell types in taste buds on the lamb epiglottis were similar to the Type I (Dark), Type II (Light), and basal cells present in oral taste buds of several mammalian species including sheep (Farbman et al., 1985; Kinnamon et al., 1985; Miller and Chaudhry, 1976; Mistretta and Bradley, 1983; Murray and Murray, 1967; Paran et al., 1975; Royer and Kinnamon, 1988, 1991; Takeda, 1976; Takeda and Hoshino, 1975; Yoshie et al., 1990). The cells in taste buds of the lamb epiglottis were also similar to previously described cells types in taste buds located in the epithelium overlying the monkey arytenoid cartilage (Idé and Munger, 1980) and mouse pharyngeal/laryngeal taste buds (Suzuki and Takeda, 1983).

Several studies have reported the presence of a third cell type which, unlike the basal cell, extends a process into the taste pore. This Type III cell has been reported to be present in the taste buds of rabbit foliate and vallate taste buds (Fujimoto and Murray, 1970; Murray, 1986; Murray and Murray, 1971; Murray et al., 1969; Royer and Kinnamon, 1991); guinea pig vallate taste buds (Yoshie et al., 1990); mouse vallate, laryngeal, and pharyngeal taste buds (Suzuki and Takeda, 1983; Takeda 1976); rat fungiform, vallate, and foliate taste buds (Uga, 1969); monkey foliate taste buds (Farbman et al., 1985); and human fungiform taste buds (Paran et al., 1975). The Type III cell is usually a slender cell and its most characteristic feature is large numbers of dense-cored vesicles scattered throughout the basal and perinuclear cytoplasm of the cell (Murray, 1986; Royer and Kinnamon, 1991). These cells are reportedly the only cells in rabbit foliate taste buds that exhibit synaptic specializations suggestive of 

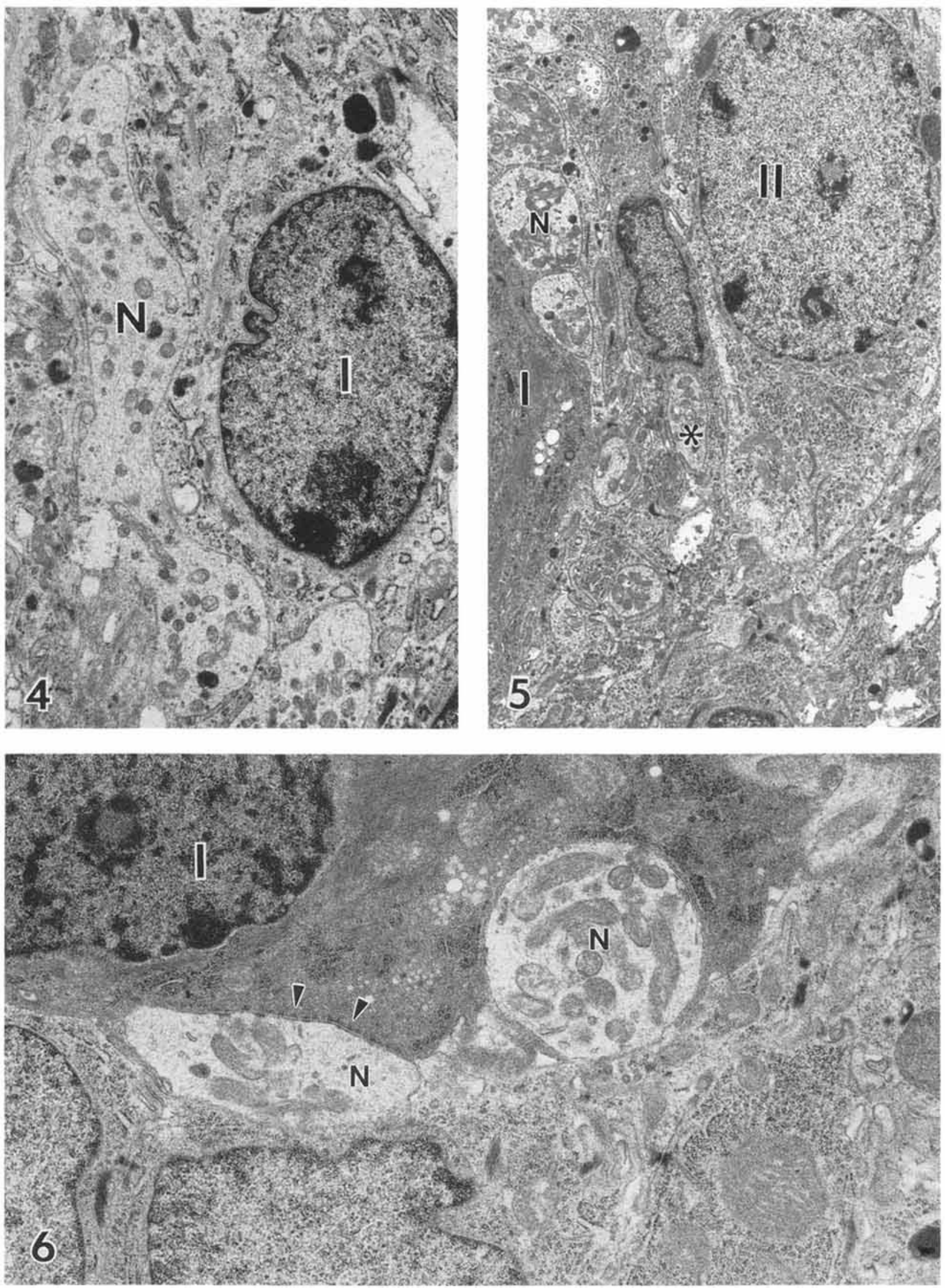

Fig. 4-6. 
chemical synapses (Murray and Murray, 1971; Royer and Kinnamon, 1991). The taste buds of the lamb epiglottis we examined did not contain a cell group equivalent to the Type III cell described by other investigators. Scattered dense-cored vesicles were occasionally observed in the cytoplasm of some of the cells of lamb epiglottal taste buds, but large perinuclear concentrations similar to those seen in rabbit and monkey foliate taste buds were never observed. Furthermore, in the taste buds we examined synaptic specializations were not restricted to one particular group of cells as has been reported for rabbit, rat and monkey foliate taste buds.

The failure to identify a distinct Type III cell group in epiglottal taste buds is not unique to lamb epiglottal taste buds. In an investigation of the development of sheep fungiform taste buds Mistretta and Bradley (1983) reported the presence of only two cell types which extended processes into the taste pore. These investigators also noted that the taste cells ended either as microvilli or blunt endings, a finding similar to the results of the present study. Idé and Munger (1980) also did not find evidence of a separate Type III cell in taste buds of the monkey arytenoid cartilage although they too describe the presence of scattered dense-cored vesicles in cells they labeled as being chemosensory (Type II). Suzuki and Takeda (1983) reported the existence of a third cell type in mouse pharyngeal and laryngeal taste buds corresponding to the Type III cell of the rabbit foliate papillae. These cells were reported to contain cytoplasmic dense-cored vesicles and were the only cells to exhibit synaptic contacts with nerves. The differences between the results reported in lamb and monkey, and those in mouse might simply reflect species differences or they could be the result of differences in the way that various investigators classify cells on the basis of certain morphological features. For example, in a study of mouse vallate taste buds Kinnamon et al. (1985) failed to observe Type III cells whereas Takeda (1976) described a separate class of cells as Type III. As noted above, we occasionally observed a Type II cell which contained numerous vesicles in the basal cytoplasm associated with specialized synaptic regions, but in no case did we observe the widespread distribution of vesicles in the perinuclear cytoplasm that is so characteristic of Type III cells in foliate taste buds (Farbman et al., 1985; Murray, 1986; Royer and Kinnamon, 1991). It may be possible that had we un-

Fig. 4. Section through a nerve process and adjacent Type I cell. The Type I cell nucleus exhibits the invaginations typical of this cell group. Note the numerous mitochondria contained within the nerve processes. Abbreviation: $\mathrm{N}$, nerve process. $\times 8,400$.

Fig. 5. Numerous nerve profiles can be seen adjacent to two Type I cells. One nerve process $\left({ }^{*}\right)$ can be seen adjacent to the Type I cell nucleus. A Type II cell can be seen at the upper right of the figure. As is normally the case, this Type II cell exhibits a more electron lucent cytoplasm and a more spherical nucleus. $\times 6,800$.

Fig. 6. Electron micrograph showing nerve processes adjacent to a very dark Type I cell. Note the membrane specializations in the form of dense projections of the taste cell membrane (arrowheads). Mitochondria and neurofilaments can be seen in the nerve processes. $\times 16,450$. dertaken a complete serial reconstruction of an entire lamb epiglottal taste bud that a Type III cell may have emerged. Of the different cell types reported to be present in the taste bud, the Type III cell constitutes only about $5-15 \%$ of the total cells (Royer and Kinnamon, 1991; Murray, 1969; Murray and Murray, 1971). Therefore it is possible that with the sampling technique used in the present study we simply did not encounter this cell group.

\section{Nerve Processes and Synapses}

The large number of nerve fibers and swellings, most of which were located in the basal two-thirds of the taste bud, is in accordance with previous observations in sheep and other mammalian oral taste buds as well as taste buds of the mouse and monkey laryngeal regions. Furthermore, these nerves were frequently imbedded in invaginations of the taste bud cell membrane near the nucleus, a finding similar to that reported for sheep fungiform papillae, guinea pig circumvallate papille, mouse and rabbit foliate taste buds, and monkey laryngeal taste buds (Idé and Munger, 1980; Mistretta and Bradley, 1983; Murray, 1973; Murray and Murray, 1967; Royer and Kinnamon, 1988, 1991). Although there were numerous close appositions between nerve fibers and adjacent cells in lamb epiglottal taste buds, relatively few of the areas of apposition exhibited any membrane specializations or concentrations of clear and dense-cored vesicles. The numerous nervecell appositions with a paucity of synaptic specializations is a characteristic of almost all taste buds regardless of their location. Many investigators have speculated that the non-specialized associations between nerve fibers and taste bud cells plays an important trophic function in maintaining the cells in the taste bud since surgically severing the nerve supply to taste buds results in degeneration of the cells in the taste bud (Farbman, 1969; Guth, 1971; Murray and Murray, 1971; Whitehead et al., 1985). Alternatively, Graziadei has hypothesized that the large numbers non-specialized associations observed between nerves and taste bud cells may reflect "transitory adaptations" of nerve fibers to the changing environment of the taste bud produced by the turnover of taste cells (Graziadei, 1969; Henkin et al., 1969).

The synaptic foci observed between cells and nerves in taste buds of the lamb epiglottis were similar in appearance to previously described synapses in oral and laryngeal taste buds. The macular shape, synaptic thickenings, dense projections, and accumulations of vesicles in the cell adjacent to membrane specializations have all been observed in taste buds of other species (Farbman et al., 1985; Gray and Watkins, 1965; Kinnamon et al., 1985; Royer and Kinnamon, 1988, 1991; Idé and Munger, 1980; Delay and Roper, 1988; Yoshie et al., 1990). The large amount of variability in the size of the synaptic membrane specializations, the number of vesicles per synapse, and the proportion of clear and dense-cored vesicles that are present at synapses in the lamb epiglottal taste buds is also not unique to this species or the location of the taste buds sampled. A similar variability has been reported for synapses located in guinea pig vallate taste buds (Yoshie et al., 1990) and rabbit foliate taste buds (Royer and Kinnamon, 1991) and it has been suggested 

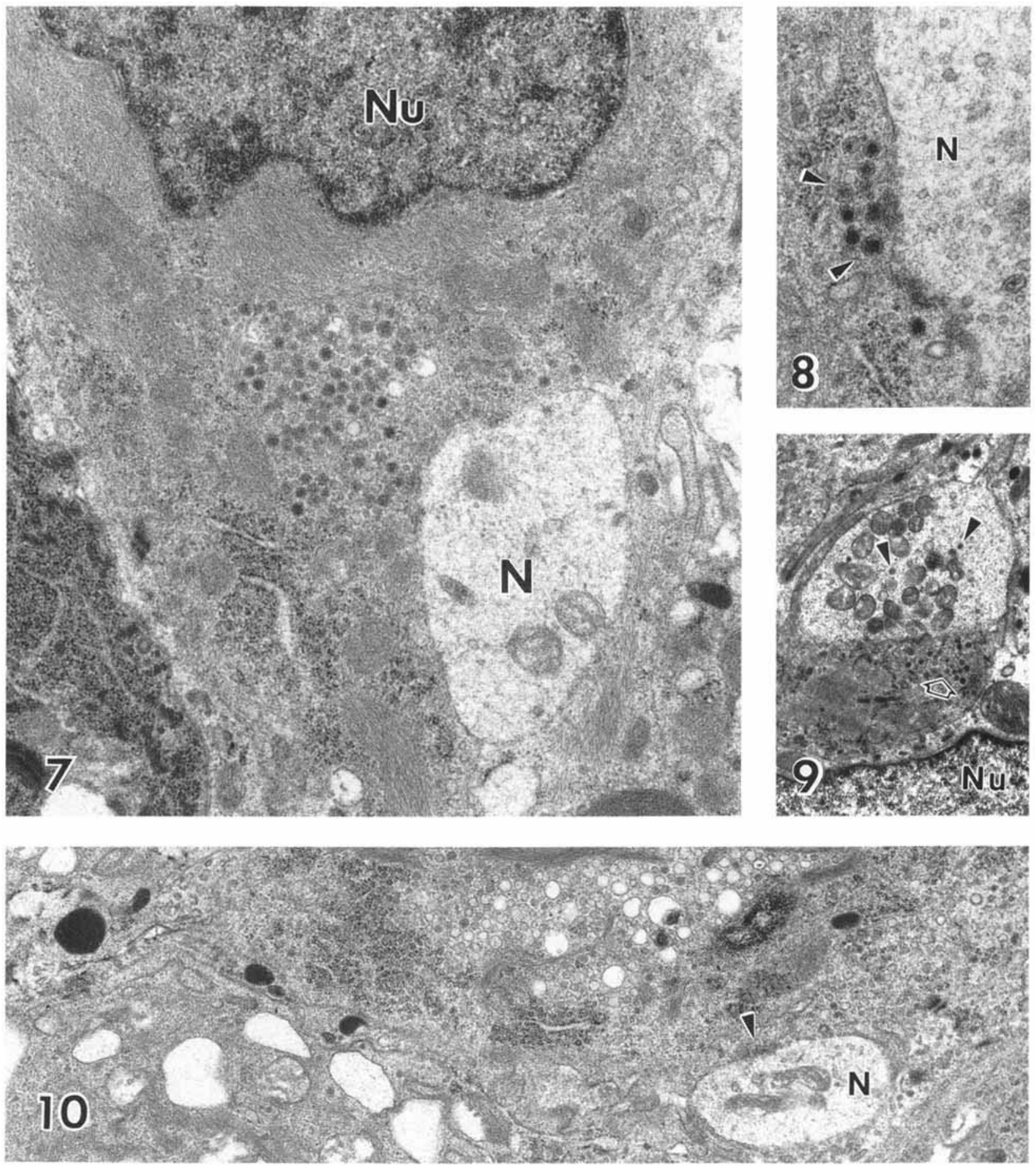

Fig. 7. Electron micrograph of a synapse between a very dark Type I cell and a nerve process. This photomicrograph shows the close relationship between the nerve process and the cell nucleus ( $\mathrm{Nu}$ ) typical of synapses throughout the taste bud. Large numbers of vesicles are located in the cell cytoplasm adjacent to the nerve process. $\times 23,650$.

Fig. 8. Synapse between a nerve process and a Type II cell. The profiles of neurotubules can be seen in the nerve process. The vesicle distribution near the apposition between the Type II cell and nerve process is relatively small and restricted (arrowheads) when compared to Figure 12. $\times 33,600$.

Fig. 9. Synapse between a Type I cell and a nerve process. Like Figure 7, this synapse is located near the cell nucleus. Most of the presynaptic vesicles are dense-cored (open arrowhead), and a few scattered vesicles (arrowheads) can be seen in the postsynaptic nerve ending. $\times 10,200$.

Fig. 10. Electron micrograph showing an apposition between a nerve process and a Type 11 cell. This cell is an example of the occasional Type II cell that contained large numbers of vesicles scattered throughout regions of the cytoplasm where the cell and nerve fiber were apposed. Both small clear and dense-cored vesicles, and large empty looking membrane bound vesicles are present as is a small thickening of the presynaptic and postsynaptic membranes in the region where the nerve fiber and cell are apposed (arrowhead). $\times 9,600$ 


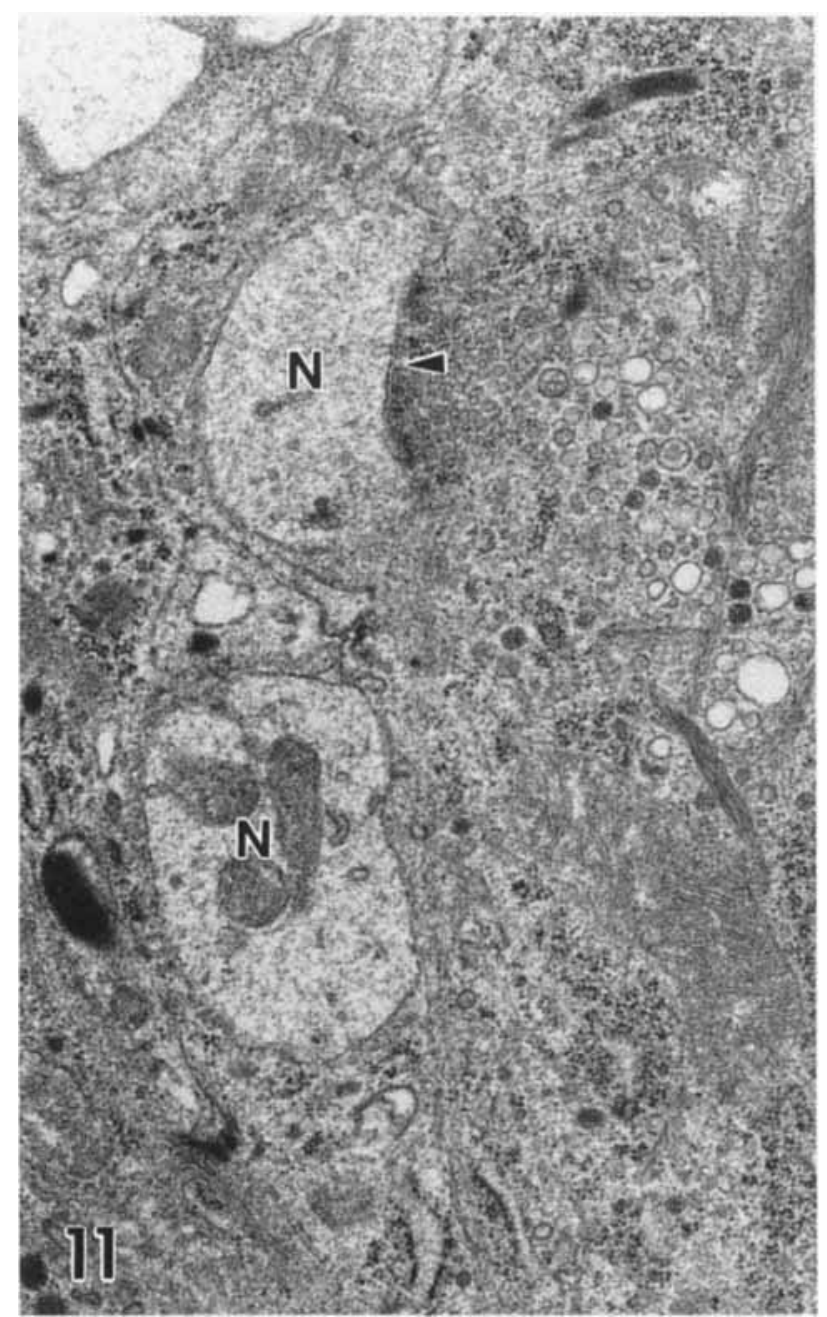

Figs. 11, 12. Electron micrographs of a serially sectioned synapse approximately $500 \mathrm{~nm}$ apart. Several nerve processes are closely apposed to this Type II cell, although only one region of membrane

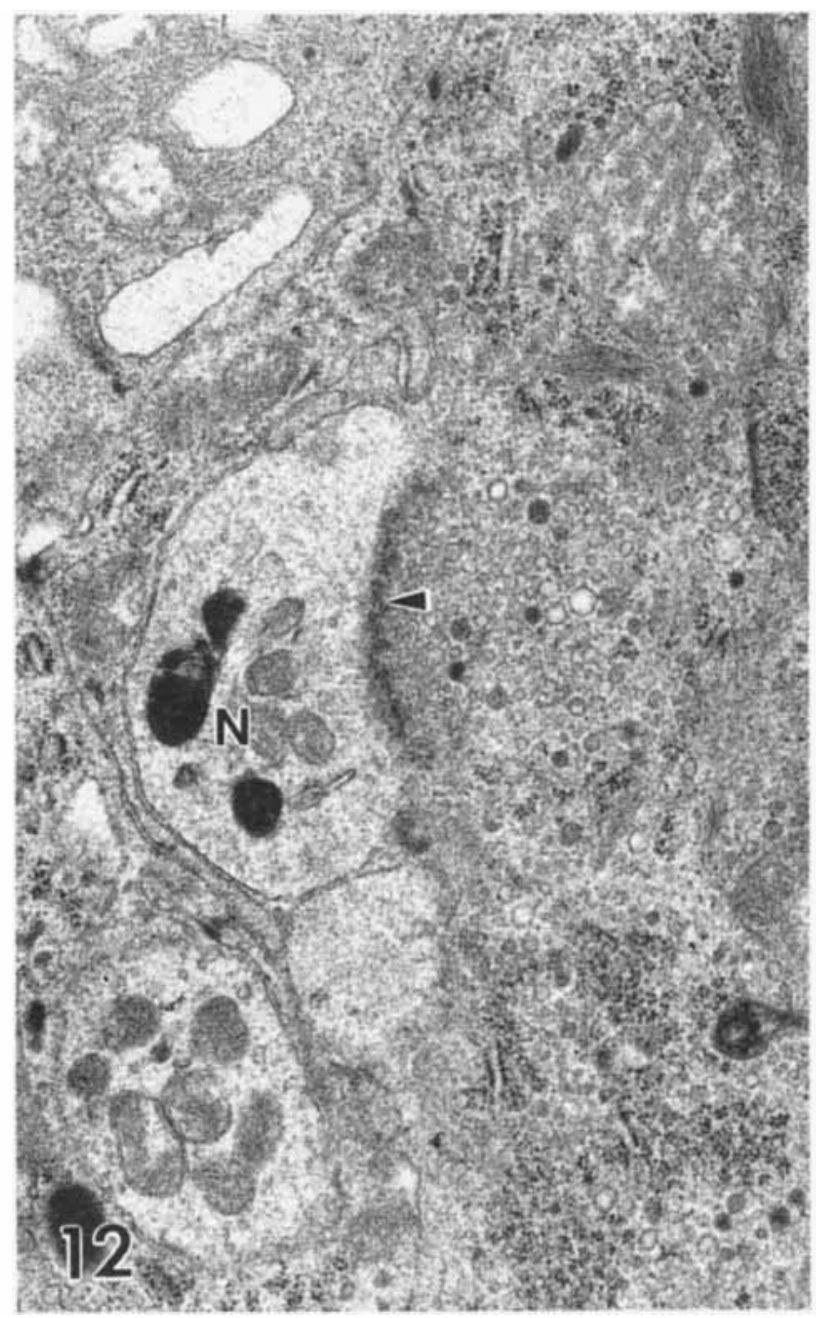

specialization can be seen in this set of electron micrographs (arrowheads). Large numbers of clear and dense-cored vesicles fill the cell cytoplasm adjacent to the nerves. $\times 22,100$. by these investigators that this variability in synaptic structure may reflect different classes of synapses that might subserve different functions.

Although occasional scattered clear and dense-cored vesicles were observed in nerve fibers that abutted the taste bud cells, we did not observe any indications of efferent, reciprocal, or axoaxonic synapses in any of the epiglottal taste buds examined. This finding is similar to descriptions of mouse vallate and circumvallate papillae where all synapses were classified as afferent, but differs from studies of monkey laryngeal taste buds and oral taste buds in guinea pig, chick, and mudpuppy where evidence of these types of contacts have been described (Delay and Roper, 1988; Ganchrow et al., 1991; Idé and Munger, 1980). The taste buds of the lamb epiglottis also lacked the finger-like synaptic contacts described in mouse vallate and mouse and rabbit foliate papillae (Royer and Kinnamon, 1988, 1991; Kinnamon et al., 1985).

A major difference between the results of the present study and previous descriptions of monkey and mouse upper airway taste buds was the presence of synaptic specializations observed in Type I cells. In the taste buds of the lamb epiglottis these synapses were generally small and restricted to regions of the cell near the nucleus (Figs. 7 and 9). The reasons for these discrepancies are not immediately apparent. In their examination of taste buds on the mouse epiglottis Suzuki and Takeda (1983) did not serially section the taste buds so it is possible that synaptic contacts between cells other than their Type III may have been missed. However, Idé and Munger (1980) did serially section taste buds on the monkey arytenoid cartilage and failed to observe synapses associated with "sustentacular" (Type I) cells. The observed difference may be due to species differences similar to that reported for mouse and rabbit foliate taste buds. In the mouse, synapses have been reported to be present on all cell types within the foliate taste bud whereas in rabbit foliate taste buds it appears that only the Type III cell exhibits synaptic contacts with nerve fibers (Murray, 1986; Royer and Kinnamon, 1988, 1991). Synapses with more than one 
type of taste cell have also been observed in mudpuppy taste buds, mouse vallate taste buds and in taste buds of some fish (Delay and Roper, 1988; Kinnamon, 1985, 1988; Reutter, 1978). The existence of synapses on both Type I and Type II cells of the lamb epiglottal taste bud suggests that both cell types are involved in laryngeal chemoreception. Since stimulation of epiglottal taste buds initiates reflexes to protect the airway, having all the cells that send processes into the taste pore involved in chemoreception would provide a larger receptor area which would be advantageous for the detection of foreign materials and would provide the best possible protection against the accidental aspiration of foods or fluids.

The taste buds located on the lamb epiglottis share many structural similarities to mammalian taste buds located in the oral cavity and other regions of the pharynx and larynx. Although the laryngeal taste buds are similar in structure to oral taste buds they exhibit sensitivities and response patterns to chemical stimuli that are considerably different from that produced by stimulation of oral cavity taste buds (Bradley, 1982; Bradley et al., 1983; Dickman and Smith, 1988; Shingai and Beidler, 1985; Smith and Hanomori, 1991; Stedman et al., 1980). Furthermore, because of the location of these taste buds it can be reasonably argued that their primary function probably has little to do with gustation and the selection of food. Rather, through differences in the detector mechanisms located at the apical portions of the taste cell membrane and afferent projections into neural pathways involved in swallowing and respiratory reflexes, the laryngeal taste buds act as chemosensory sentinels that protect the animal from accidentally aspirating ingested foods and fluids.

\section{ACKNOWLEDGMENTS}

This work supported by NIH grant DC00735 to R.D.S. and a grant from the University Michigan Undergraduate Research Opportunity Program to B.M.K.

\section{LITERATURE CITED}

Boggs, D. F., and D. Bartlett, Jr. 1982 Chemical specificity of a laryngeal apneic reflex in puppies. J. Appl. Physiol., 53:455-462.

Bradley, R.M. 1982 The role of epiglottal and lingual chemoreceptors: a comparison. In: Determination of Behaviour by Chemical Stimuli. J.E. Steiner and J.R. Ganchrow, eds. IRL Press, London, pp. $37-45$.

Bradley, R.M., M.L. Cheal, and Y.H. Kim 1980 Quantitative analysis of developing epiglottal taste buds in sheep. J. Anat. 130:25-32.

Bradley, R.M., and Y.H. Kim 1977 Quantitative morphological changes in epiglottal taste buds over the life span of the sheep. Ann. Rech. Vet., 8:492-494.

Bradley, R.M., H.M. Stedman, and C.M. Mistretta 1983 Superior laryngeal nerve response patterns to chemical stimulation of sheep epiglottis. Brain Res., 276:81-93.

Davies, A.M., J.S. Koenig, and B.T. Thach 1988 Upper airway chemoreflex responses to saline and water in preterm infants. J. Appl. Physiol., 64:1412-1420.

Delay, R.J., and S.D. Roper 1988 Ultrastructure of taste cells and synapses in the mudpuppy Necturus maculosus. J. Comp. Neurol., 277:268-280.

Dickman, J.D., and D.V. Smith 1988 Response properties of fibers in the hamster superior laryngeal nerve. Brain Res., 450:25-38.

Farbman, A.I. 1965 Fine structure of the taste bud. J. Ultrastruct. Res., 12:328-350.

Farbman, A.I. 1969 Fine structure of degenerating taste buds after denervation. J. Embryol. Exp. Morph., 22:55-68.

Farbman, A.I., G. Hellekant, and A. Nelson 1985 Structure of taste buds in foliate papillae of the rhesus monkey. Am. J Anat 172 41-56.

Fujimoto, S., and R.G. Murray 1970 Fine structure of degeneration and regeneration in denervated rabbit vallate taste buds. Anat. Rec., 168:393-413.

Ganchrow, D., J.R. Ganchrow, and R.S. Goldstein 1991 Ultrastructure of palatal taste buds in the perihatching chick. Am. J. Anat., 192:69-78.

Gray, E.G., and K.C. Watkins 1965 Electron microscopy of taste buds in the rat. Z. Zellforsch., 66:583-595.

Graziadei, P.P.C. 1969 The ultrastructure of taste buds in mammals In: Second Symposium on Oral Sensation and Perception. J.F. Bosma, ed. Charles C. Thomas, Springfield, pp. 5-35.

Grogaard, J., D.P. Lindstrom, M.T. Stahlman, F. Marchal, and H. Sundell 1982 The cardiovascular response to laryngeal water administration in young lambs. J. Dev. Physiol., 4:353-370.

Guth, L. 1971 Degeneration and regeneration of taste buds. In: Handbook of Sensory Physiology, vol. 4. L.M. Beidler, ed. SpringerVerlag, New York, pp. 63-74.

Harding, R. 1984 Function of the larynx in the fetus and newborn. Annu. Rev. Physiol., 46:645-659.

Harding, R., P. Johnson, and M.E. McClelland 1978 Liquid-sensitive laryngeal receptors in the developing sheep, cat and monkey. J. Physiol., 277:409-422.

Harding, R., P. Johnson, M.E. McClelland, C.N. McLeod, and P.L. Whyte 1977 Laryngeal function during breathing and swallowing in foetal and new-born lambs. J. Physiol., 272:14-15.

Henkin, R.I., P.P.C. Graziadei, and D.F. Bradley 1969 The molecular basis of taste and its disorders. Ann. Intern. Med., 71:791-821.

Idé, C., and B.L. Munger 1980 The cytologic composition of primate laryngeal chemosensory corpuscles. Am. J. Anat., 158:193-209.

Johnson, P., D.M. Salisbury, and A.T. Storey 1975 Apnoea induced by stimulation of sensory receptors in the larynx. In: Development of Upper Respiratory Anatomy and Function: Implications for Sudden Infant Death Syndrome. J.F. Bosma and J. Showacre, eds. U.S. Government Printing Office, Washington, D.C., pp. 160183.

Kinnamon, J.C., T.A. Sherman, and S.D. Roper 1988 Ultrastructure of mouse vallate taste buds: III. Patterns of synaptic connectivity. J. Comp. Neurol., 270:1-10.

Kinnamon, J.C., B.J. Taylor, R.J. Delay, and S.D. Roper 1985 Ultrastructure of mouse vallate taste buds. I. Taste cells and their associated synapses. J. Comp. Neurol., 253:48-60.

Kovar, I., U. Selstam, W.Z. Catterton, M.T. Stahlman, and H.W. Sundell 1979 Laryngeal chemoreflex in newborn lambs: respiratory and swallowing response to salts, acids, and sugars. Pediat. Res., 13:1144-1149.

Lalonde, E.R., and J.A. Eglitis 1961 Number and distribution of taste buds on the epiglottis, pharynx, larynx, soft palate and uvula in a human newborn. Anat. Rec., 140:91-95.

Lee, J.C., B.J. Stoll, and S.E. Downing 1977 Properties of the laryngeal chemoreflex in neonatal piglets. Am. J. Physiol., 233:R30R36.

Lucier, G.E., A.T. Storey, and B.J. Sessle 1979 Effects of upper respiratory tract stimuli on neonatal respiration: reflex and single neuron analyses in the kitten. Biol. Neonate, 35:82-89.

Miller, R.L., and A.P. Chaudhry 1976 Comparative ultrastructure of vallate, foliate and fungiform taste buds of golden Syrian hamster. Acta Anat. 95:75-92.

Mistretta, C.M., and R.M. Bradley 1983 Neural basis of developing salt taste sensation: response changes in fetal, postnatal, and aduit sheep. J. Comp. Neurol., 215:199-210.

Murray, R.G. 1973 The ultrastructure of taste buds. In: The Ultrastructure of Sensory Organs. I. Friedmann, ed. Elsevier, New York, pp. 1-81.

Murray, R.G. 1986 The mammalian taste bud type III cell: a critical analysis. J. Ultrastruct. Molecul. Struct. Res., 95:175-188.

Murray, R.G., and A. Murray 1967 Fine structure of taste buds of rabbit foliate papillae. J. Ultrastruct. Res., 19:327-353.

Murray, R.G., and A. Murray 1971 Relations and possible significance of taste bud cells. Contributions to Sensory Physiology, 5:47-95.

Murray, R.G., A. Murray, and S. Fujimoto 1969 Fine structure of gustatory cells in rabbit taste buds. J. Ultrastruct. Res., 27:444461.

Nakano, T., and H. Muto 1986 Distribution and probable functional role of taste buds located in the intermediate epithelium on the mouse arytenoid region. Okajimas Folia Anat. Jpn., 63:81-92.

Paran, N., C.F.T. Mattern, and R.I. Henkin 1975 Ultrastructure of the taste bud of the human fungiform papilla. Cell Tissue Res., 161: $1-10$

Pickens, D.L., G. Schefft, and B.T. Thach 1988 Prolonged apnea as- 
sociated with upper airway protective reflexes in apnea of prematurity. Am. Rev. Resp. Dis., 137:113-118.

Reutter, K. 1978 Taste organ in the bullhead (Teleostei). Adv. Anat. Embryol. and Cell Biol., 55:1-98.

Roper, S.D. 1989 The cell biology of vertebrate taste receptors. Annu. Rev. Neurosci., 12:329-353.

Royer, S.M., and J.C. Kinnamon 1991 HVEM serial-section analysis of rabbit foliate taste buds: I. Type III cells and their synapses. J. Comp. Neurol., 306:49-72.

Royer, S.M., and J.C. Kinnamon 1988 Ultrastructure of mouse foliate taste buds: synaptic and nonsynaptic interactions between taste cells and nerve fibers. J. Comp. Neurol., 270:11-24.

Shingai, T., and L.M. Beidler 1985 Response characteristics of three taste nerves in mice. Brain Res., 355:245-249.

Smith, D.V., and T. Hanamori 1991 Organization of gustatory sensitivities in hamster superior laryngeal nerve fibers. J. Neurophysiol., 65:1098-1114.

Stedman, H.M., R.M. Bradley, C.M. Mistretta, and B.E. Bradley 1980 Chemosensitive responses from the cat epiglottis. Chem. Senses, $5: 233-245$.

Stedman, H.M., C.M. Mistretta, and R.M. Bradley 1983 A quantitative study of cat epiglottal taste buds during development. J. Anat., 136:821-827.

Storey, A.T. 1968 A functional analysis of sensory units innervating epiglottis and larynx. Exp. Neurol., 20:366-383.

Storey, A.T., and P. Johnson 1975 Laryngeal water receptors initiating apnea in the lamb. Exp. Neurol., 47:42-55.

Suzuki, Y., and M. Takeda 1983 Ultrastructure and monoamine precursor uptake of taste buds in pharynx, nasopalatine ducts, epiglottis and larynx of the mouse. Acta Anat. Nippon., 58:593-605.

Sweazey, R.D., and R.M. Bradley 1986 Central connections of the lingual-tonsillar branch of the glossopharyngeal nerve and the superior laryngeal nerve in lamb. J. Comp. Neurol., 245:471482.

Sweazey, R.D., and R.M. Bradley 1988 Response of lamb nucleus of the solitary tract neurons to chemical stimulation of the epiglottis. Brain Res., 439:195-210.

Sweazey, R.D., and R.M. Bradley 1989a Responses of neurons in the lamb nucleus tractus solitarius to stimulation of the caudal oral cavity and epiglottis with different stimulus modalities. Brain Res., 480:133-150.

Sweazey, R.D., and R.M. Bradley 1989b Response characteristics of lamb trigeminal neurons to stimulation of the oral cavity and epiglottis with different sensory modalities. Brain Res. Bull., 22 . 883-891.

Takeda, M. 1976 An electron microscopic study on the innervation in the taste buds of the mouse circumvallate papillae. Arch. Histol. Jpn., 39:257-269.

Takeda, M., and T. Hoshino 1975 Fine structure of taste buds in the rat. Arch. Histol. Jpn., 37:395-413.

Thach, B.T., A.M. Davies, J.S. Koenig, A. Menon, and D.L. Pickens 1990 Reflex induced apneas. Prog. Clin. Biol. Res., 345:77-87.

Travers, S.P., and K. Nicklas 1990 Taste bud distribution in the rat pharynx and larynx. Anat. Rec., 227:373-379.

Uga, S. 1969 A study on the cytoarchitecture of taste buds of rat circumvallate papillae. Arch. Histol. Jpn., 31:59-72.

Whitehead, M.C., C.S. Beeman, and B.A. Kinsella 1985 Distribution of taste and general sensory nerve endings in fungiform papillae of the hamster. Am. J. Anat., 173:185-202.

Wilson, J.G. 1905 The structure and function of the taste-buds of the larynx. Brain, 28:339-351.

Yoshie, S., C. Wakasugi, Y. Teraki, and T. Fujita 1990 Fine structure of the taste bud in guinea pigs. I. Cell characterization and in nervation patterns. Arch. Histol. Cytol., 53:103-119. 